\title{
Self-management behavior and fasting plasma glucose control in patients with type 2 diabetes mellitus over 60 years old: Multiple effects of social support on quality of life
}

\section{Xinye Qi}

Harbin Medical University School of Health Management

Jiao Xu

Harbin Medical University School of Health Management

\section{Guiying Chen}

Harbin Medical University First Affiliated Hospital Department of Cardiology

Huan Liu

Harbin Medical University School of Health Management

Jingjing Liu

Harbin Medical University School of Health Management

Jiahui Wang

Harbin Medical University School of Health Management

\section{Xin Zhang}

Harbin Medical University School of Public Health

\section{Yanhua Hao}

Harbin Medical University School of Health Management

Qunhong Wu ( $\nabla$ wuqunhong@163.com )

Harbin Medical University https://orcid.org/0000-0002-2873-5266

\section{Mingli Jiao}

Harbin Medical University School of Health Management

\section{Research}

Keywords: Elderly, Hypoglycemia, Quality of Life, Patient Self-Management, Social Support

Posted Date: October 9th, 2020

DOI: https://doi.org/10.21203/rs.3.rs-87544/v1

License: (c) (1) This work is licensed under a Creative Commons Attribution 4.0 International License.

Read Full License 
Version of Record: A version of this preprint was published at Health and Quality of Life Outcomes on November 12th, 2021. See the published version at https://doi.org/10.1186/s12955-021-01881-y. 


\section{Abstract}

Objective: Elderly patients with type 2 diabetes mellitus are highly vulnerable due to serious complications. Thus far, there is little research on the relationship between social support and quality of life, which warrants further exploration of the internal mechanism. This study assessed quality of life and its interfering factors in this patient population.

Methods: In total, 571 patients with type 2 diabetes mellitus over 60 years old were recruited from two community clinics in Heilongjiang province, China. We collected data on health status, quality of life, selfmanagement behavior, fasting plasma glucose (FPG) level, and social support. Structural equation modeling and the bootstrap method were used to analyze the data.

Results: The average quality of life score was $-29.25 \pm 24.41$. Poorly scored domains of quality of life were "Psychological feeling" (-8.67), "Activity" (-6.36), and "Emotion" (-6.12). Of the 571 patients, 65.32\% had normal FPG, 9.8\% had high-risk FPG, $15.94 \%$ had good self-management behavior, and $22.07 \%$ had poor social support. Significant correlations among social support, self-management behavior, FPG level, and quality of life were noted. A multiple mediator model revealed that social support influenced quality of life in three ways: (i) directly $\left(c^{\prime}=0.6549\right)$; (ii) indirectly through self-management behavior (a1*b1 = $0.2596)$; and (iii) indirectly through FPG control $(a 2 * b 2=0.2825)$. Self-management behavior influenced quality of life directly and indirectly through FPG control.

Conclusion: Improving self-management behavior and monitoring hypoglycemia should become priority targets for future intervention. Scheduled social support to self-management projects should be put into the standardized management procedure. Physicians should provide substantial and individualized support to elderly patients with type 2 diabetes mellitus regarding medication, blood glucose monitoring, and physical exercise.

\section{Introduction}

The incidence of type 2 diabetes mellitus has been growing rapidly as a consequence of lifestyle changes, urbanization, and aging. Type 2 diabetes mellitus accounts for $90 \%$ of diabetes cases worldwide [1], and the global prevalence of adult diabetes has increased dramatically from $4.7 \%$ in 1980 to $9.0 \%$ in 2014 [2]. Sixty percent of the increment was expected to occur in developing countries [3]. The global prevalence of type 2 diabetes mellitus among the elderly is approximately $40 \%$, indicating that it a serious public health issue [4]. In China, the number of adult patients with diabetes has increased from $0.67 \%$ in 1979 to $2.7 \%$ in 2002 and to $11.6 \%$ in $2010[5,6]$. Similar to the global trends, the proportion of elderly patients with type 2 diabetes mellitus in China has increased from $10.2 \%$ in 2000 to $13.6 \%$ in $2006,20.4 \%$ in 2007, and $22.86 \%$ in 2010 [5-7]. Diabetes is characterized by severe chronic complications that can impose a heavy economic burden on patients and decrease their quality of life[8]. With a gradually declining physical condition and increasingly poor economic status, the elderly may have difficulty in self-managing their health, thus becoming a vulnerable population [9]. Therefore, the 
quality of life of elderly patients with type 2 diabetes mellitus should receive more attention from medical staff and the society.

Previous researchers have studied the relationship between social support and quality of life in diabetes $[10,11]$. Social support refers to spiritual or material support from people such as family, friends, and colleagues. Excellent social support is the basis for improving the quality of life, as it plays an essential role in relieving mental pressure, eliminating psychological obstacles, enhancing the effects of therapy, and optimizing the prognosis. Given the complexity of diabetes and its various complications, burdensome self-management activities such as daily diet, physical activity, blood glucose monitoring, and medication adherence are essential. The purpose of self-management is to control the disease and improve the quality of life. Health care professionals should provide advice and guidance on selfmanagement. However, the ability and willingness of patients to manage their own health are the main determinants of successful metabolic control [12]. In recent years, the Chinese government has paid close attention to the management of diabetes, including diabetes screening and healthy lifestyle promotion, but little progress has been made. More than a quarter of patients with diabetes have poor selfmanagement, and only $32-49 \%$ of patients have adequately controlled blood glucose levels $[5,13]$. Poor social support to the elderly may lead to unrecognized complications, irregular treatment, and poor selfmanagement behavior. In turn, poor self-management behavior may cause persistent hyperglycemia/hypoglycemia or glucose level fluctuation. Consequently, there is growing interest in finding effective ways to enhance self-management in elderly patients with type 2 diabetes mellitus.

The treatment of diabetes is complex and multidisciplinary [14]. Its three main goals are as follows: (i) to control complications; (ii) to prevent hyperglycemia/hypoglycemia; and (iii) to maintain a patient's quality of life. Adequate blood glucose control can not only prevent and reduce the complications of diabetes but also decrease the probability and risk of hypoglycemia. However, it is worth noting that there is a general lack of attention to hypoglycemia in the treatment of diabetes. Patients with diabetes often feel nervous or embarrassed if faced with hyperglycemia, but hypoglycemia is usually ignored [15]. The incidence of hypoglycemia in patients with diabetes over 65 years old is $50 \%$ greater than that in patients with diabetes under 65 years old [16]. Elderly patients have difficulty in perceiving hypoglycemia due to functional impairment of the nervous system, which lowers the blood glucose threshold sensitivity and increases the occurrence of severe hypoglycemia [17]. Therefore, avoiding hypoglycemia in elderly patients with type 2 diabetes should be the priority.

Furthermore, some studies in elderly patients with type 2 diabetes mellitus have shown that close attention to postprandial blood glucose (PBG) may also help achieve adequate blood glucose control without increasing the risk of fasting hypoglycemia [18]. However, in middle-aged patients, FPG and PBG increase simultaneously; therefore, treatment should take both indicators into account [19]. In China, the rate of blood glucose self-monitoring in elderly patients with type 2 diabetes mellitus is only $21.4 \%$, and hypoglycemia occurs in $30 \%$ of patients. The occasional occurrence of hypoglycemia or abnormal fluctuation of blood glucose in elderly patients with type 2 diabetes mellitus might have substantial, negative, and even serious clinical effects [20]. 
Most previous studies have focused on single variables. However, there is little research on the relationship between social support and quality of life, and further exploration of the internal mechanism of multiple variables has seldom been conducted. This study aimed to assess the relationships between social support, self-management behavior, FPG level, and quality of life in elderly patients with type 2 diabetes mellitus. The results of this study provide scientific evidence to develop more targeted intervention programs as well as a valuable reference for other countries to deal with the challenges of type 2 diabetes mellitus in the elderly.

\section{Methods}

\section{Participants}

Patients with type 2 diabetes mellitus were recruited from the Jianhua community, Qiqihar city, China between June and December 2012. The inclusion criteria were as follows: a) a diagnosis of type 2 diabetes mellitus made by a physician at least 1 year before the study; $b$ ) self-manage their health ; and c) age $>60$ years old. The exclusion criteria were as follows: a) acute or chronic inflammatory disease; b) cancer; and c) type 1 diabetes mellitus. All participants signed a formal consent form before enrolment into this study.

\section{Procedures}

Survey and standard investigation procedures were carried out to ensure the uniformity of data collection. First, chronic illness records of type 2 diabetes mellitus patients were reviewed and their eligibility was evaluated. Second, elderly patients with type 2 diabetes mellitus were encouraged to participate in the program after having been explained the purpose of the study. Third, appointments were scheduled for the participants to complete the questionnaire. At this point, the researchers elaborated on the purpose of the study and confirmed the eligibility of the patients. Patients who agreed to participate in the study signed a formal consent form. Data of the following variables were also collected: age, sex, race, education, income level, marital status, age at disease onset, duration of diabetes, FPG level, social support, self-management behavior, and quality of life.

\section{Measures}

\section{Perceived level of social support}

The Multidimensional Scale of Perceived Social Support (MSPSS) developed by Zimet and colleagues [21] was used to measure patient perception of social support. The scale contains 12 items evaluating three dimensions of support: family (including parents, children, and spouse [items $3,4,8$, and 11]); friends (items 6, 7, 9, and 12); and others (including neighbors and doctors [items 1, 2, 5, and 10]). Each item was scored on a 5 -point scale ranging from 1 (strongly disagree) to 5 (strongly agree), with the total score ranging from 12 to 60 [22]. A higher score indicates better overall social support. Previous studies have demonstrated the reliability of MSPSS, with Cronbach's a ranging from 0.85 to 0.94 [21, 23-25]. Test-retest reliability was evaluated over a $2-3$-month interval $(r=0.72-0.85)$ [26]. In this study, 
Cronbach's a was $0.855,0.835,0.841$, and 0.929 for each of the subscales and the overall scale, respectively.

\section{Quality of life}

The Adjusted Diabetes-specific Quality of Life Scale (CN-ADDQOL), Chinese version, was used after cultural adaptation and revision of the original scale [27]. The scale consists of 19 items and five dimensions: leisure activities ( 1 to 5 ), emotional feelings (6 to 9), psychological feelings (10 to 14), family living conditions (15 to 17$)$, and diet $(18,19)$. The participants were requested to evaluate their actual situation and the importance of each item. For example, item 10 is, "If I would not have diabetes, what would my physical appearance be like?"; options were very good (-3 points), good (-2 points), satisfactory (-1 point), the same as now (0 points), and worse than now (I point). For the importance of "my physical appearance," options were very important (3 points), important (2 points), somewhat important (1 point), and not important at all ( 0 points). If the participant chose very good and very important, respectively, the score of this item was $-3 \star 3=-9[28,29]$. The total score ranged from -171 to 57 , with a higher score indicating a better quality of life [30,31]. Cronbach's a for the original scale was $0.81-0.941$ [27, 32-34], and the relative fitting index (CFI) of the structural equation model was 0.96 [35]. In this study, Cronbach's a for CN-ADDQOL was 0.885 .

\section{Self-management behavior}

A modified version of the Type 2 Diabetes Self-care Scale (2-DSCS) developed by Toobert et al. and Wang et al. to measure diabetes self-management behavior [36] was used in this study. The modified scale comprises 26 items encompassing six dimensions: diet ( 6 items), exercise (4 items), medication (3 items), blood glucose monitoring ( 4 items), foot care ( 5 items), and hypo/hyperglycemia (4 items). Items were scored from 1 (never) to 5 (always) [23, 37]. The total score ranged from 26 to 130 , with a higher score indicating a higher level of self-management. To facilitate the comparison of data, the score index (score index $=$ actual total score/possible highest score ${ }^{\star} 100 \%$ ) and the standard score (standard score $=$ actual score/possible highest score ${ }^{\star} 100$ ) of each dimension were also calculated. A score index or standard score $<60 \%$ was considered poor, $60-80 \%$ was considered medium, and $>80 \%$ was considered good [37]. Cronbach's a for 2-DSCS was $0.82-0.88$, and test-retest reliability was good, at $0.92-0.96$ [38, 39]. In this study, Cronbach's a for each of the six dimensions was $0.919,0.891,0.863,0.836,0.783$, and 0.844 , respectively; the total scale had good internal consistency (Cronbach's $\mathrm{a}=0.880$ ).

\section{FPG level}

FPG is an important indicator of hypoglycemia and hyperglycemia. Values $>3.1 \mathrm{mmol} / \mathrm{L}$ are considered relatively safe (the occurrence of hypoglycemia is improbable). Chinese guidelines for diabetes prevention do not recommend strict blood glucose control in elderly patients with type 2 diabetes mellitus $[14,40,41]$. The Chinese guidelines for Diabetes Prevention and Control (2017 edition) specifically recommends the following FPG levels: $5.0-7.2 \mathrm{mmol} / \mathrm{L}$ for healthy elderly patients with type 2 diabetes mellitus, $5.0-8.3 \mathrm{mmol} / \mathrm{L}$ for elderly patients with type 2 diabetes mellitus and a complicated health status, and 5.6-10.0 mmol/L for elderly patients with type 2 diabetes mellitus and an extremely complicated health status. In the morning of the scheduled appointment, a blood sample was obtained 
from each patient. Twelve-hour FPG levels were assessed according to World Health Organization (WHO) standardized fingertip prock test procedures using calibrated blood glucose meters and reagent strips [41]. In this study, an FPG level of 5.0-8.3 mmol/L was defined as successful FPG control, and $\geq$ $10 \mathrm{mmol} / \mathrm{L}$ was defined as poor FPG control.

\section{Data analysis}

Statistical analyses were performed using SPSS, version 17.0, and structural equation modeling (SEM) was conducted using AMOS 17.0. Missing data were imputed by expectation maximization (EM) using SPSS missing value analysis. Descriptive statistics were used to summarize patient characteristics and measured variables.

The SEM was deemed suitable for developing a model to explain relationships among the study variables based on the variance/covariance matrix using maximum likelihood estimation. The hypothesized model was evaluated using the following multiple criteria of goodness-of-fit: a) $\chi^{2} / d f \leq 2$; b) comparative fit index (CFI) > 0.95 [38]; c) goodness-of-fit index (GFI) > 0.90; d) normed-fit index (NFI) > 0.90; and e) root mean square error of approximation (RMSEA) $<0.06$. This analytic approach allows for sequential examination of two mediators, while simultaneously testing the indirect effects of each mediator independently [42]. Variables with non-significant factor loadings were deleted from the structural equation model. Chi-square difference tests and the Akaike information criterion (AIC) were used to compare the alternate model and the theoretical model [43]. A two-tailed $p$-value of 0.05 was considered to indicate statistical significance.

The hypothesis was put forward that with control of these indirect paths, the direct relationship between social support and quality would be substantially reduced. Path analysis was conducted to evaluate all indirect pathways from social support to quality of life by inspecting the direction and magnitude of path coefficients. All the one-way paths were considered (eFigure1 in the Supplement). We examined the direct pathway from social support to quality of life (Arrow A) and also investigated whether this relationship could be explained partially by indirect effects through diabetes self-management (Arrows B and C) or FPG level (Arrows D and E). Additionally, a double-mediator pathway from social support to quality of life by both self-management (primary mediator) and FPG level (secondary mediator; Arrows B, F, and E) was investigated.

The bootstrap method was used to test the multiple mediating effects of the hypothesized model $[44,45]$. All specific and conditional indirect effects were subjected to follow-up bootstrap analyses [45].

\section{Results}

\section{Patient characteristics}

A total of 571 patients with a mean duration of type 2 diabetes mellitus of $8.23 \pm 6.85$ years were enrolled in this study. Their general characteristics and scores of quality of life are shown in Table 1. Among the 571 patients, $22.07 \%$ had poor-to-moderate social support; $33.62 \%$ had poor self-management behavior 
while $15.94 \%$ had good self-management; and $14.69 \%$ had poorly controlled FPG levels ( $\geq 10.0 \mathrm{mmol} / \mathrm{L})$, while $65.32 \%$ had successful FPG control (5.0-8.3 mmol/L). Patients with low-to-moderate social support and poor self-management behavior had the lowest quality of life scores, followed by those with FPG $>16.7 \mathrm{mmol} / \mathrm{L}$ and those who never engaged in physical exercise. The constituent ratios for each item of the MSPSS and 2-DSCS are shown in eFigure2 and eFigure3 in the Supplement, respectively. The specific scores for each dimension of self-management behavior and social support are shown in

eTable1 in the Supplement. Among the patients with poor self-management behavior, $60.8 \%, 50.1 \%$, and $40.8 \%$ had poor exercise management, poor blood glucose monitoring ability, and poor FPG control over hypo/hyperglycemia, respectively. More than $20 \%$ of those patients reported poor social support. Quality of life, social support, and self-management behavior data are summarized in eTable2 in the Supplement. 
Table 1

Descriptive statistics for the total sample and scores of quality of life in elderly patients with type 2 diabetes mellitus with different demographic characteristics $(n=571)$.

\begin{tabular}{|c|c|c|}
\hline Variable & $\mathrm{n}(\%)$ & Quality of life score (mean \pm SD) \\
\hline \multicolumn{3}{|l|}{ Age, years } \\
\hline $60-64$ & $147(25.74)$ & $-33.16 \pm 26.11$ \\
\hline $65-69$ & $129(22.59)$ & $-28.06 \pm 22.84$ \\
\hline $70-74$ & $159(27.85)$ & $-29.27 \pm 25.49$ \\
\hline $75-79$ & 89 (15.59) & $-26.15 \pm 21.47$ \\
\hline$>80$ & $47(8.23)$ & $-26.05 \pm 19.81$ \\
\hline \multicolumn{3}{|l|}{ Sex } \\
\hline Men & $191(33.45)$ & $-28.50 \pm 23.23$ \\
\hline Women & 380 (66.55) & $-29.62 \pm 24.56$ \\
\hline \multicolumn{3}{|l|}{ Education } \\
\hline$<$ High school & $309(54.12)$ & $-27.60 \pm 21.41$ \\
\hline High school & $207(36.25)$ & $-32.36 \pm 26.27$ \\
\hline >High school & $55(9.63)$ & $-26.74 \pm 28.83$ \\
\hline \multicolumn{3}{|l|}{ Marital status } \\
\hline Single & $6(1.05)$ & $-29.22 \pm 18.13$ \\
\hline Married & $465(81.44)$ & $-29.70 \pm 25.06$ \\
\hline Divorced & $18(3.15)$ & $-26.89 \pm 19.13$ \\
\hline Widowed & $82(14.36)$ & $-27.19 \pm 19.72$ \\
\hline \multicolumn{3}{|c|}{ Frequency of physical exercise } \\
\hline Never & $23(4.03)$ & $-34.77 \pm 37.13$ \\
\hline Occasionally & $44(7.71)$ & $-32.69 \pm 27.12$ \\
\hline Irregular & $183(32.05)$ & $-30.52 \pm 23.91$ \\
\hline Frequently & $203(35.54)$ & $-28.64 \pm 25.16$ \\
\hline All the time & $118(20.67)$ & $-25.95 \pm 19.17$ \\
\hline
\end{tabular}

Abbreviations. $\mathrm{FPG}=$ fasting plasma glucose; $\mathrm{PBG}=$ postprandial blood glucose; $\mathrm{SD}=$ standard deviation. Notes. The bold font indicates poor quality of life; " based on the score index and the standard score. 


\section{Variable}

\section{Level of social support}

Low to moderate

High

Self-management behavior ${ }^{\#}$

Bad

Medium

Good

FPG, $\mathrm{mmol} / \mathrm{L}$

3.9-5.0

$5.0-8.3$

$8.3-16.7$

$>16.7$

PBG, $\mathrm{mmol} / \mathrm{L}$

$\leq 7.8$

$7.8-11.1$

$>11.1$

\section{Duration of diabetes, years}

$\leq 1$

$1-3$

3-5

5-10

$\otimes 10$

Mean \pm SD

Complications

No

Yes $n(\%)$

Quality of life score (mean \pm SD)

\begin{tabular}{ll}
$126(22.07)$ & $-44.66 \pm 26.03$ \\
\hline $445(77.93)$ & $-24.88 \pm 22.09$
\end{tabular}

192 (33.62)

$-40.71 \pm 26.35$

288 (50.44)

$-25.39 \pm 21.72$

91 (15.94)

$-16.38 \pm 17.31$

57 (9.98)

$-24.66 \pm 19.69$

373 (65.32)

$-28.14 \pm 24.31$

137 (23.99)

$-33.94 \pm 24.40$

$4(0.70)$

$-36.83 \pm 36.51$
76 (13.31)

213 (37.30)

282 (49.39)
$-21.84 \pm 20.76$

$-25.80 \pm 21.85$

$92(16.11)$

$-29.17 \pm 21.29$

65 (11.38)

149 (26.10)

$-32.12 \pm 25.42$

170 (29.77)

$-32.76 \pm 25.88$

$8.23 \pm 6.85$

$-29.25 \pm 24.41$

$-28.66 \pm 25.96$

$-25.42 \pm 20.59$

$-32.29 \pm 25.67$

$8.23 \pm 6.85$

99 (17.34)

$-20.23 \pm 12.35$

472 (82.66)

$-31.07 \pm 25.47$

Abbreviations. $\mathrm{FPG}=$ fasting plasma glucose; $\mathrm{PBG}=$ postprandial blood glucose; $\mathrm{SD}=$ standard deviation. Notes. The bold font indicates poor quality of life; " based on the score index and the standard score. 


\section{Preliminary analysis: Bivariate analysis}

The results of bivariate analysis are shown in eTable 2 in the Supplement. All correlations were significant. Tolerance values ranged from 0.693 to 0.804 , and variance inflation factor (VIF) values changed from 1.244 to 1.443 . Further, case analysis revealed no evidence of outliers. The results of correlation analysis provided the basis for testing the mediation effect.

\section{Multiple Mediation Analysis}

Baron and Kenny's mediation effect testing procedure was used to verify the hypothesis model. Model 1 was a theoretical model depicting each path between social support and quality of life with mediators (self-management behavior and FPG). Three competitive models (Model 2, Model 3, and Model 4) and one alternative model (Model 5) were also analyzed.

The fit indices of Models 1, 2, 3, 4, and 5 are shown in Table 2. Compared to other models, Model 1 showed good fit and all paths were significant (eTable3 in the Supplement). Therefore, it was considered the best model to match the observation data (Fig. 1).

Table 2

Comparison of different structural equation models.

\begin{tabular}{|c|c|c|c|c|c|c|c|c|}
\hline Model & Description & $\chi^{2}$ & DF & GFI & NFI & CFI & IFI & RMSEA \\
\hline 1 & $\begin{array}{l}\text { Hypothetical mediation } \\
\text { model }\end{array}$ & 238.01 & 85 & 0.948 & 0.956 & 0.971 & 0.971 & 0.056 \\
\hline 2 & $\begin{array}{l}\text { Deletion of path from SM to } \\
\text { QOL }\end{array}$ & 259.05 & 86 & 0.943 & 0.952 & 0.968 & 0.968 & 0.059 \\
\hline 3 & $\begin{array}{l}\text { Deletion of path from SM to } \\
\text { QOL and from SM to FPG }\end{array}$ & 280.17 & 87 & 0.939 & 0.948 & 0.964 & 0.964 & 0.062 \\
\hline 4 & $\begin{array}{l}\text { Deletion of path from SM to } \\
\text { FPG }\end{array}$ & 273.97 & 86 & 0.940 & 0.950 & 0.965 & 0.965 & 0.062 \\
\hline 5 & $\begin{array}{l}\text { Alternative model: SS, SM, } \\
\text { and FPG directly affect QOL }\end{array}$ & 384.57 & 88 & 0.914 & 0.929 & 0.944 & 0.945 & 0.077 \\
\hline \multicolumn{9}{|c|}{$\begin{array}{l}\text { Abbreviations. DF = degrees of freedom; GFI = goodness-of-fit index; NFI = normed-fit index; } \mathrm{CFI}= \\
\text { comparative fit index; IFI = incremental fit index; RMSEA = root mean square error of approximation; } \\
\text { SM = self-management behavior; SS = social support; QOL = quality of life; FPG = fasting plasma } \\
\text { glucose. }\end{array}$} \\
\hline
\end{tabular}

Paths from social support to self-management ( $\mathrm{a} 1=0.329, p<0.001)$, FPG level (a2 $=-0.186, p<0.001)$, and quality of life ( $\left.c^{\prime}=0.496, p<0.001\right)$ were significant. The path coefficients from self-management activity to FPG level $(\mathrm{a} 3=-0.260, p<0.001)$ and quality of life $(\mathrm{b} 1=0.422, p<0.001)$ were significant. The path coefficient from FPG level to quality of life $(b 2=0.697, p<0.001)$ was also significant. 


\section{Significance test of the mediation effect}

The estimates and bootstrapped $95 \%$ confidence intervals (Cls) of the indirect effects were the paths verified for mediation (Table 3). The finalized structural model (Fig. 1) revealed that the paths from social support to quality of life through self-management and FPG levels were significant. Point estimates for indirect effects and $95 \%$ bias-corrected Cls for multiple mediation analyses revealed that selfmanagement and FPG level were mediators in the path between social support and quality of life.

Table 3

Bootstrap test results.

\begin{tabular}{|c|c|c|c|c|c|c|}
\hline Mediation path & SE & $\begin{array}{l}\text { Boot } \\
\text { SE }\end{array}$ & $\mathbf{P}$ & $\begin{array}{l}95 \% \mathrm{Cl}, \\
\text { lower limit }\end{array}$ & $\begin{array}{l}95 \% \mathrm{Cl}, \\
\text { upper limit }\end{array}$ & Effect \\
\hline $\mathrm{SS} \rightarrow \mathrm{SM} \rightarrow \mathrm{QOL}(\mathrm{a} 1 * \mathrm{~b} 1)$ & 0.2596 & 0.0906 & 0.0042 & 0.1355 & 0.5175 & $31.50 \%$ \\
\hline $\begin{array}{l}\mathrm{SS} \rightarrow \mathrm{SM} \rightarrow \mathrm{FPG} \rightarrow \mathrm{QOL} \\
(\mathrm{a} 1 * \mathrm{a} 3 * \mathrm{~b} 2)\end{array}$ & 0.1128 & 0.0379 & 0.0029 & 0.0606 & 0.2249 & $13.69 \%$ \\
\hline $\mathrm{SS} \rightarrow \mathrm{FPG} \rightarrow \mathrm{QOL}(\mathrm{a} 2 * \mathrm{~b} 2)$ & 0.2825 & 0.0886 & 0.0014 & 0.1556 & 0.4974 & $34.28 \%$ \\
\hline $\mathrm{SS} \rightarrow \mathrm{QOL}\left(\mathrm{c}^{\prime}\right)$ & 0.6549 & 0.1723 & 0.0001 & 0.4199 & 1.0577 & $79.48 \%$ \\
\hline \multicolumn{7}{|c|}{ 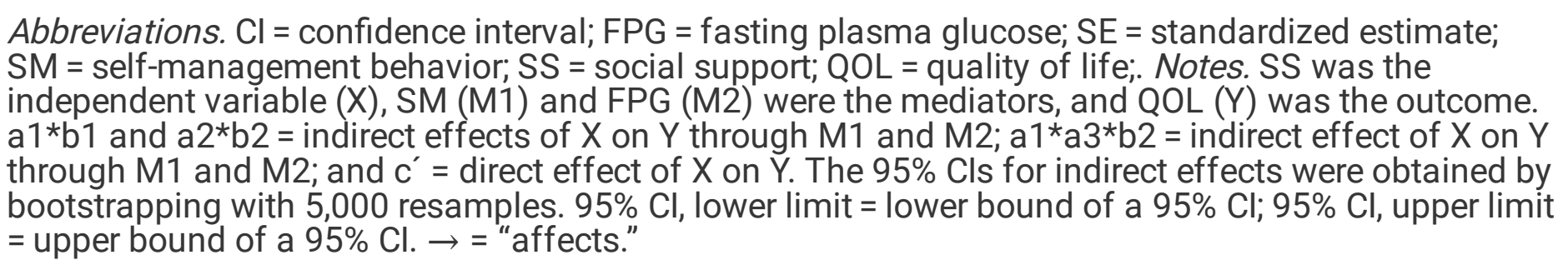 } \\
\hline
\end{tabular}

In the path $\mathrm{SS} \rightarrow \mathrm{SM} \rightarrow \mathrm{QOL}(\mathrm{a} 1 * \mathrm{~b} 1)$, the standardized estimate was $0.2596(95 \% \mathrm{Cl}[0.1355,0.5175], p=$ 0.0042 ), indicating that self-management behavior played a mediating role in the influence of social support on quality of life. In the path $\mathrm{SS} \rightarrow \mathrm{FPG} \rightarrow \mathrm{QOL}(\mathrm{a} 2 * \mathrm{~b} 2)$, the standardized estimate was 0.2825 $(95 \% \mathrm{Cl}[0.1556,0.4974], p=0.0014)$, indicating that FPG level played a mediating role in the influence of social support on quality of life. In the path $\mathrm{SS} \rightarrow \mathrm{SM} \rightarrow \mathrm{FPG} \rightarrow \mathrm{QOL}(\mathrm{a} 1 * \mathrm{a} 3 * \mathrm{~b} 2)$, the standardized estimate was $0.1128(95 \% \mathrm{Cl}[0.0606,0.2249], p=0.0029)$, indicating that social support affected selfmanagement behavior, which, in turn, affected quality of life indirectly through the FPG level. In the path $\mathrm{SS} \rightarrow \mathrm{QOL}\left(\mathrm{c}^{\prime}\right)$, the direct effect of social support on quality of life (controlling for the mediators) was $0.6549(95 \% \mathrm{Cl}[0.4199,1.0577], p=0.0001)$, indicating that self-management behavior and FPG had a mediating effect in the influence of social support on quality of life.

\section{Discussion}

Substantial research has shown a high prevalence of type 2 diabetes mellitus among the elderly. Many of these patients have low quality of life, frequent complications, and poor health outcomes. However, little is known about the factors associated with quality of life in this patient population. 


\section{Social support, self-management behavior, and quality of life in elderly patients with type 2 diabetes mellitus}

In this study, the total score of social support in elderly patients with type 2 diabetes mellitus was $43.40 \pm$ 8.41; family support scored the highest $(14.75 \pm 2.99)$ in the three dimensions of perceived social support, indicating that the main source of support was the patient's family. This finding was consistent with those of other studies [46]. Indeed, family plays a major role in patient care. Further analysis revealed that only $58.4-67.1 \%$ of patients received specific social support. Moreover, the proportion of patients who could not obtain sufficient support from family, friends, and others was $21.4 \%, 24.0 \%$, and $25.4 \%$, respectively. This means that community nurses and physicians may not be providing social support to the elderly. To improve the overall level of social support to the elderly, one should focus on the development of support resources available outside the family, as well as exploit potential support from relatives, colleagues, friends, medical staff, and other patients. There is an imperative demand for clinicians to strengthen clinical guidance for providing psychological counseling and emotional support in addition to the treatment of diabetes and its complications. Community nurses and physicians should provide reliable information and emotional support to the elderly through lectures and psychological interventions.

Diabetes is a disease requiring long-term treatment, which also requires patients to control their diet and self-monitor their blood glucose level. Therefore, self-management of diabetes is of vital importance. In this study, the standard score of self-management behavior was 66.32; the top three self-management dimensions with poor score index were exercise (60.8\%), blood glucose monitoring (50.1\%), and hyperglycemia/hypoglycemia management $(40.8 \%)$. The proportion of patients with good diet control, regular exercise, medication management, blood glucose monitoring, foot care, and hyperglycemia/hypoglycemia management was $16.1 \%, 5.8 \%, 38.2 \%, 19.4 \%, 20.8 \%$, and $31.3 \%$, respectively. These results indicated that engagement in physical exercise and blood glucose monitoring were weak in elderly patients with type 2 diabetes mellitus [27].

Elderly patients with type 2 diabetes mellitus had moderate quality of life $(-29.25 \pm 24.41)$; poorly scored dimensions of quality of life were "Psychological feeling" (-8.67), "Activity (-6.36)," and "Emotion' (-6.12). At the same time, $82.66 \%$ of patients reported complications, indicating that the quality of life in elderly patients with type 2 diabetes mellitus in China is poor [33]. This was consistent with the findings of previous studies $[14,47]$. Interestingly, the group with low social support (score $=-44.66$ ) and in that with poor self-management behavior (score $=-40.71$ ) had a score that was $43.66 \%$ and $39.71 \%$ lower than the average (score $=-29.25$ ), respectively. That is to say, elderly patients with type 2 diabetes mellitus may experience inadequate social support and poor self-management, which may affect quality of life.

\section{Importance of FPG monitoring}

Glycated hemoglobin (HbA1c), FPG, and PBG are the main clinical monitoring indicators for diabetes mellitus. HbA1c reflects long-term blood glucose control, which is essential to avoid diabetes complications [48]. The long-term balance of blood glucose in patients with diabetes is emphasized 
clinically, which may lead to misinterpretation and hypoglycemia events during treatment [49-51]. Although $\mathrm{HbA} 1 \mathrm{c}$ was used as a control target for long-term blood glucose monitoring, it cannot reflect the level of instantaneous blood glucose. Moreover, it has been confirmed that blood glucose fluctuations in elderly patients with diabetes are extremely harmful. Changes in human blood glucose lead to changes in systolic and diastolic blood pressure, which is a great challenge for fragile blood vessels such as those of the elderly. Therefore, blood glucose fluctuation cannot be ignored in the elderly population. Regular blood glucose monitoring is key.

In this study, FPG was considered more suitable for blood glucose monitoring in elderly patients. First, FPG is closer related to HbA1c than PBG $[52,53]$. PBG increases and decreases depending on FPG. From this point of view, the control of FPG is thought to be more effective than that of PBG, for the former serves as the basis of individualized treatment. Second, the LANMET study has suggested that FPG has a linear relationship with $\mathrm{HbA} 1 \mathrm{c}$, and $\mathrm{HbA} 1 \mathrm{c}$ increases with increased FPG and decreases with decreased FPG. A level of FPG of $5.6 \mathrm{mmol} / \mathrm{L}$ promotes $\mathrm{HbA1c} 7 \%$ to reach the target [54]. Thirdly, FPG is a major determinant of cardiovascular disease [55-57]. The recurrent fluctuation of FPG will lead to frequent hypoglycemia, cause an abnormal increase in sympathetic nerve excitability, and increase the incidence and mortality of cerebrovascular diseases [58]. Carlene et al. found that each 1-mmol// decrease of FPG was associated with a $21 \%$ lower risk of stroke and a $23 \%$ lower risk of ischemic heart disease [59]. Moreover, as FPG variability increases, all-cause mortality and cardiovascular disease mortality also increase $[60,61]$. Therefore, this study focused on FPG.

In particular, $9 \%$ of elderly patients with type 2 diabetes mellitus kept their FPG at a very strict level between $3.9 \mathrm{mmol} / \mathrm{L}$ and $5.6 \mathrm{mmol} / \mathrm{L}$. However, it might be dangerous to multi-vulnerable patients because it might result in hypoglycemia, causing dysfunctional osmolality and a range of consequences [62], including death [63]. Therefore, the control of FPG should be not too strict to avoid the possibility of a hypoglycemia crisis. When hypoglycemia occurs and remains unnoticed for a certain period, irreversible body injury may occur [64]. It is of equal importance to keep close attention to both high and low FPG levels. This study showed that only $19.4 \%$ of patients had good self-management of FPG level. This should be listed as a priority target for intervention.

\section{Mechanism of attention to FPG control}

Correlation analysis revealed that the FPG level was negatively correlated with social support $(r=-0.289$, $p<0.01)$ and quality of life $(r=-0.451, p<0.01)$. The inverse association between FPG level and quality of life indicated that better FPG control level was associated with a higher quality of life and better social support. Further multi-mediation analysis results showed that social support exerted not only a direct effect on quality of life but also an indirect effect through the path SS $\rightarrow F P G \rightarrow Q O L$ (a2*b2). The standardized estimate was $0.2825(p=0.0014)$, indicating that FPG had a mediation role in the influence of social support on quality of life. The indirect effect of social support on quality of life through monitoring of FPG was significant. 
The above study demonstrated that social support available from doctors, family, and friends was an important potential resource for diabetes interventions, which should be paid high attention. There is an urgent need to explore the effective way to mobilize more actively, timely, persistent, and greater social support from families and the society.

This study found that only $65.32 \%$ of elderly patients with type 2 diabetes mellitus were under the control of FPG, which was consistent with the findings of previous studies [18]. This might be explained by the path $\mathrm{SS} \rightarrow \mathrm{FPG} \rightarrow \mathrm{QOL}$. With persistent and disease fluctuations and complications (82.66\%), this could lead to poor quality of life. Their average scores were particularly poor in the psychological, activity, and emotional domains. Patients felt boresome, psychological and emotional fatigue, and more easily troublesome to talk and seek help from their family members or friends, resulting in their poor use of support. However, insufficient social support might, in turn, exert additional impact on FPG, and causing elderly diabetes patients more difficulty in keeping regular monitoring of blood glucose. Many patients measure only their blood glucose when they are not feeling well. Additionally, the long-term cost of regular self-monitoring blood glucose may also be very high for elderly patients. Therefore, mobilizing both external support (resources for regular monitoring) and subjective support (actions for regular monitoring) to achieve the target of monitoring FPG, preventing hypoglycemia, and improving the quality of life should be emphasized [65].

\section{Mechanism of emphasis self-management activity}

Correlation analysis showed that self-management behavior is positively correlated with social support ( $r$ $=0.323, p<0.01)$ and quality of life $(r=0.369, p<0.01)$. This is consistent with previous findings that better self-management activity is associated with a higher quality of life and better social support [12]. Further multi-mediation analysis results showed, in the path $S S \rightarrow S M \rightarrow Q O L$ ( $a 1 * b 1)$, that the influence of social support through self-management behavior on quality of life was $0.2596(p=0.0042)$, indicating that self-management behavior played a mediation role in the influence of social support on quality of life. The indirect effect of social support on quality of life through self-management behavior was significant. That is to say, self-management behavior is an important promoting factor, which can positively contribute to the influence of social support on quality of life. One possible explanation is that self-monitoring of blood glucose is an important part of diabetes treatment. It is an important basis for doctors to formulate a hypoglycemic program for patients and an important reference for patients to observe blood glucose changes, which can effectively avoid the occurrence of hyperglycemia and hypoglycemia. As an important mediator, it can either enhance or reduce the impact of social support on quality of life, which highlights the value of improving self-management activity among elderly patients with type 2 diabetes mellitus.

However, this study showed that only $15.94 \%$ of patients had high-quality self-management, while $84.06 \%$ had moderate or poor self-management; moreover, more than $20 \%$ of patients reported inadequate social support. The study found that elderly patients with type 2 diabetes mellitus were unable to self-manage their health, including physical exercise and diet, which could contribute to poor quality of life. Previous studies have mentioned the need for dietary and medication guidance [66, 67]. 
However, our study found that exercise and mental health guidance for the elderly are still inadequate. Hence, to improve the quality of life in elderly patients with type 2 diabetes mellitus, doctors are required to educate their patients about self-management. Guidance on regular exercise, self-blood glucose monitoring, and management of hypo/hyperglycemia should be provided during routine appointments.

A relationship between FPG level, self-management, and quality of life was also observed. Correlation analysis revealed that FPG level was negatively correlated with self-management behavior $(r=-0.322, p<$ 0.01). Further multi-mediation analysis results showed, in the path $\mathrm{SS} \rightarrow \mathrm{SM} \rightarrow \mathrm{FPG} \rightarrow \mathrm{QOL}\left(\mathrm{a} 1{ }^{*} \mathrm{a} 3{ }^{*} \mathrm{~b} 2\right)$, that the standardized estimate was $0.1128(p=0.0029)$. This indicated that the mediation path was established in that order.

The indirect effect of self-management behavior on quality of life through FPG was significant. Poor selfmanagement behavior might result in non-timely monitoring of the FPG level, which, in turn, might reduce quality of life. Glycemic control is partly dependent upon the regular completion of several selfmanagement behaviors, including exercise, dietary modification, foot care, self-monitoring of blood glucose, and medication adherence. Attention to tailored social support targeted at the weakest areas of self-management, especially FPG control, should be strengthened.

\section{Limitations of research}

This study had a few limitations. First, as a cross-sectional study, the relationships between variables were only correlative, and causal relationships could not be established. Second, this study was performed at Heilongjiang province, and patients were recruited from city communities. Therefore, the findings of this study might differ from those of rural areas. Third, the MSPSS and 2-DSCS were revised in this study. Hence, the reliability of the scales requires further validation, despite good internal consistency. Fourth, this study focused on perceived social support by elderly patients. Actual social support was not analyzed. With the development and abundance of social support resources, a specific social support scale for elderly patients with type 2 diabetes mellitus should be developed. In this study, some patients had difficulty in understanding some questions from the CN-ADDQOL, for the scale needs further modification. Further studies with a larger, more diverse sample and more variables such as actual social support and specific self-management are needed.

\section{Conclusion}

Elderly patients with type 2 diabetes mellitus had poor quality of life, fasting blood glucose control, and self-management. Our study identified four important pathways constituting a complicated, interwoven network contributing to poor quality of life in elderly patients with type 2 diabetes mellitus. It also revealed the internal mechanism between key variables of social support, self-management behavior, FPG level, and quality of life. The following key interconnected paths were identified: $S S \rightarrow S M \rightarrow Q O L$, $\mathrm{SS} \rightarrow \mathrm{FPG} \rightarrow \mathrm{QOL}, \mathrm{SS} \rightarrow \mathrm{SM} \rightarrow \mathrm{FPG} \rightarrow \mathrm{QOL}$, and $\mathrm{SS} \rightarrow \mathrm{QOL}$.

Both social support and self-management behavior should be priority targets for future intervention. Particular attention should be paid to the quality of life and hypoglycemia in elderly patients with type 2 
diabetes mellitus. These factors should be taken into consideration when developing personalized treatment and standardized management procedures.

\section{Declarations}

\section{Ethics approval and consent to participate}

The study was approved by the Committee on the Ethics of Harbin Medical University.

\section{Consent for publication}

Not applicable.

\section{Availability of data and materials}

Not applicable.

\section{Competing interests}

No potential conflicts of interest relevant to this article were reported.

\section{Funding}

This study was funded by the National Natural Science Foundation of China (Grant No.71333003).

\section{Authors' contributions}

$X Y Q$ designed the study and was a major contributor in writing the manuscript. J $X$ and GY C colleted the data; H L, JJ L analysed the data; JH W, X Z interpreted the results; YH H, QH W, and ML J conceived of the study, designed the study. All authors discussed the results and revised the manuscript.

\section{Acknowledgments}

The authors are very grateful to Li Yang for providing the suggestion to draft the manuscript. We thank all of the participating organizations and participants, without their co-operation and suggestions, the authors won't be able to complete this academic research.

\section{References}

1. Guariguata L, Whiting DR, Hambleton I, Beagley J, Linnenkamp U, Shaw JE: Global estimates of diabetes prevalence for 2013 and projections for 2035. Diabetes Res Clin Pract 2014, 103:137-149.

2. Organization WH: Global Report on Diabetes. Working Papers 2016.

3. Shaw JE, Sicree RA, Zimmet PZ: Global estimates of the prevalence of diabetes for $\mathbf{2 0 1 0}$ and 2030. Diabetes Res Clin Pract 2010, 87:4-14. 
4. Zuo H, Shi Z, Hussain A: Prevalence, trends and risk factors for the diabetes epidemic in China: a systematic review and meta-analysis. Diabetes Res Clin Pract 2014, 104:63-72.

5. Xu Y, Wang L, He J, Bi Y, Li M, Wang T, Wang L, Jiang Y, Dai M, Lu J, et al: Prevalence and control of diabetes in Chinese adults. JAMA 2013, 310:948-959.

6. Yang W, Lu J, Weng J, Jia W, Ji L, Xiao J, Shan Z, Liu J, Tian H, Ji Q, et al: Prevalence of diabetes among men and women in China. N Engl J Med 2010, 362:1090-1101.

7. Yu S, Sun Z, Zheng L, Guo X, Yang H, Sun Y: Prevalence of Diabetes and Impaired Fasting Glucose in Hypertensive Adults in Rural China: Far from Leveling-Off. Int J Environ Res Public Health 2015, 12:14764-14779.

8. Bragg F, Holmes MV, lona A, Guo Y, Du H, Chen Y, Bian Z, Yang L, Herrington W, Bennett D, et al: Association Between Diabetes and Cause-Specific Mortality in Rural and Urban Areas of China. JAMA 2017, 317:280-289.

9. Chew BH, Ghazali SS, Ismail M, Haniff J, Bujang MA: Age $>/=60$ years was an independent risk factor for diabetes-related complications despite good control of cardiovascular risk factors in patients with type 2 diabetes mellitus. Exp Gerontol 2013, 48:485-491.

10. Bishwajit G, Tang S, Yaya S, He Z, Feng Z: Lifestyle Behaviors, Subjective Health, and Quality of Life Among Chinese Men Living With Type 2 Diabetes. Am J Mens Health 2017, 11:357-364.

11. Jin Y, Ding L, Wang Q, He L, Nie M, Song X, Tang H, Guo D, Chen Y, Yao Y: [Factors affecting the quality of life of elderly diabetic patients: survey in north and south Wanjiang river regions]. Nan Fang Yi Ke Da Xue Xue Bao 2014, 34:283-285. (in Chinese)

12. Luo X, Liu T, Yuan X, Ge S, Yang J, Li C, Sun W: Factors Influencing Self-Management in Chinese Adults with Type 2 Diabetes: A Systematic Review and Meta-Analysis. Int J Environ Res Public Health 2015, 12:11304-11327.

13. Ji LN, Lu JM, Guo XH, Yang WY, Weng JP, Jia WP, Zou DJ, Zhou ZG, Yu DM, Liu J, et al: Glycemic control among patients in China with type 2 diabetes mellitus receiving oral drugs or injectables. BMC Public Health 2013, 13:602.

14. Society CD: Guidelines for the prevention and control of type 2 diabetes in China (2017 Edition). Chinese Journal of Practical Internal Medicine 2018, 1:4-67. (in Chinese)

15. Umpierrez GE, Pasquel FJ: Management of Inpatient Hyperglycemia and Diabetes in Older Adults. Diabetes Care 2017, 40:509-517.

16. E Miller M, E Bonds D, Gerstein H, R Seaquist E, Bergenstal R, Calles-Escandon J, Dale Childress R, Craven T, M Cuddihy R, Dailey G, et al: The effects of baseline characteristics, glycaemia treatment approach, and glycated haemoglobin concentration on the risk of severe hypoglycaemia: Post hoc epidemiological analysis of the ACCORD study. BMJ 2010, 340:b5444.

17. Barrot-de la Puente J, Mata-Cases M, Franch-Nadal J, Mundet-Tuduri X, Casellas A, Fernandez-Real $\mathrm{JM}$, Mauricio D: Older type 2 diabetic patients are more likely to achieve glycaemic and cardiovascular risk factors targets than younger patients: analysis of a primary care database. Int $J$ Clin Pract 2015, 69:1486-1495. 
18. Albright TL, Parchman M, Burge SK, Investigators RR: Predictors of self-care behavior in adults with type 2 diabetes: an RRNeST study. Fam Med 2001, 33:354-360.

19. Fu S, Chen W, Luo L, Ye P: Roles of fasting and postprandial blood glucose in the effect of type 2 diabetes on central arterial stiffness: a 5-year prospective community-based analysis. Diabetol Metab Syndr 2017, 9:33.

20. Rodbard HW, Jellinger PS, Davidson JA, Einhorn D, Garber AJ, Grunberger G, Handelsman Y, Horton ES, Lebovitz H, Levy P, et al: Statement by an American Association of Clinical Endocrinologists/American College of Endocrinology consensus panel on type 2 diabetes mellitus: an algorithm for glycemic control. Endocr Pract 2009, 15:540-559.

21. Zimet GD, Powell SS, Farley GK, Werkman S, Berkoff KA: Psychometric characteristics of the Multidimensional Scale of Perceived Social Support. J Pers Assess 1990, 55:610-617.

22. Ladaninejad S, llali E, Mousavinasab N, Taraghi Z: The Relationship between Depressive Symptoms and Demographic-Medical Characteristics among Elder People with Cancer. Asia Pac J Oncol Nurs 2019, 6:424-430.

23. Yang L, Wu Q, Hao Y, Cui Y, Liang L, Gao L, Jiao M, Ning N, Sun H, Kang ZJQoLR: Self-management behavior among patients with diabetic retinopathy in the community: a structural equation model. 2016, 26:1-8.

24. Guan NC, Seng LH, Hway Ann AY, Hui KO: Factorial validity and reliability of the Malaysian simplified Chinese version of Multidimensional Scale of Perceived Social Support (MSPSS-SCV) among a group of university students. Asia Pac J Public Health 2015, 27:225-231.

25. Chou K-L: Assessing Chinese adolescents' social support: the multidimensional scale of perceived social support. Personality and Individual Differences 2000, 28:299-307.

26. Blumenthal JA, Burg MM, Barefoot J, Williams RB, Haney T, Zimet G: Social support, type A behavior, and coronary artery disease. Psychosom Med 1987, 49:331-340.

27. Kong D, Ding Y, Zuo X, Su W, Xiu L, Lin M, Rao S, Yu S: Adaptation of the Audit of DiabetesDependent Quality of Life questionnaire to people with diabetes in China. Diabetes Res Clin Pract 2011, 94:45-52.

28. Swee Sung S, Yen GS, Mong BY, Jiat Ling P, Chuen LS, Julian T, Hwee Lin WJAHE, Policy H: Audit of Diabetes-Dependent Quality of Life (ADDQoL) [Chinese Version for Singapore] questionnaire: reliability and validity among Singaporeans with type 2 diabetes mellitus. 2010, 8:239-249.

29. Ostini R, Dower J, Donald M: The Audit of Diabetes-Dependent Quality of Life 19 (ADDQoL): feasibility, reliability and validity in a population-based sample of Australian adults. Qual Life Res 2012, 21:1471-1477.

30. Sundaram M, Kavookjian J, Patrick JH, Miller LA, Madhavan SS, Scott VG: Quality of life, health status and clinical outcomes in Type 2 diabetes patients. Qual Life Res 2007, 16:165-177.

31. Kuznetsov L, Long GH, Griffin SJ, Simmons RK: Are changes in glycaemic control associated with diabetes-specific quality of life and health status in screen-detected type 2 diabetes patients? Fouryear follow up of the ADDITION-Cambridge cohort. Diabetes Metab Res Rev 2015, 31:69-75. 
32. Wang HF, Bradley C, Chang TJ, Chuang LM, Yeh MC: Assessing the impact of diabetes on quality of life: validation of the Chinese version of the 19-item Audit of Diabetes-Dependent Quality of Life for Taiwan. Int J Qual Health Care 2017, 29:335-342.

33. Fung CS, Wan EY, Yu CL, Wong CK: Validity and reliability of the 19-item Audit of Diabetes-Dependent Quality of Life (ADDQoL-19) questionnaire in Chinese patients with type 2 diabetes mellitus in primary care. Qual Life Res 2016, 25:2373-2378.

34. Wei GF, Cao MJ. (2016). [An assumption of community type 2 diabetes health intervention based on the pattern of PRECEDE-PROCEED]. Chinese Journal of Modern Nursing, 22(4), 479-482. (in Chinese)

35. Kong DL, Zhang GE, Pan HY, Hu LR, Ding YL. (2007). [The reliability and validity evaluation on the Chinese version of the audit of diabetes dependent quality of life scale]. Chinese Journal of Chronic Disease Prevention and Control, 15(3), 202-204. (in Chinese).

36. Toobert DJ, Hampson SE, Glasgow RE: The summary of diabetes self-care activities measure: results from 7 studies and a revised scale. Diabetes Care 2000, 23:943-950.

37. Huang M, Zhao R, Li S, Jiang X: Self-management behavior in patients with type 2 diabetes: a crosssectional survey in western urban China. PLoS One 2014, 9:e95138.

38. Wang JS, Wang RH, Lin CC: Self-care behaviors and related factors in outpatients newly diagnosed with non-insulin-dependent diabetes mellitus. The Journal of Nursing 1998, 45:60-74.

39. Wang JQ, Liu M. (2003). [The relationship between self-efficacy and self-care among type $\mathbb{\Delta}$ diabetes patients. Chinese Journal of Nursing]. 38(6), 429-431. (in Chinese).

40. Society CD: Guidelines for the prevention and control of type 2 diabetes in China (2010 Edition). Chinese Journal of Practical Internal Medicine 2011, 1:4-67. (in Chinese)

41. Society CD: Guidelines on prevention and treatment of type 2 diabetes in China (basic version). 2012. (in Chinese)

42. Preacher KJ, Hayes AF: Asymptotic and resampling strategies for assessing and comparing indirect effects in multiple mediator models. Behav Res Methods 2008, 40:879-891.

43. Baron RM, Kenny DA: The moderator-mediator variable distinction in social psychological research: conceptual, strategic, and statistical considerations. J Pers Soc Psychol 1986, 51:1173-1182.

44. Taylor AB, MacKinnon DP, Tein J-Y: Tests of the Three-Path Mediated Effect. Organizational Research Methods 2007, 11:241-269.

45. Lau RS, Cheung GW: Estimating and Comparing Specific Mediation Effects in Complex Latent Variable Models. Organizational Research Methods 2010, 15:3-16.

46. Kaya U, Caydam O: Association between social support and diabetes burden among elderly patients with diabetes: A cross-sectional study from Turkey \% J Saudi Journal of Medicine and Medical Sciences. 2019.

47. Gregg EW, Engelgau MM, Narayan V: Complications of diabetes in elderly people. BMJ 2002, 325:916-917. 
48. Huang ES, Laiteerapong N, Liu JY, John PM, Moffet HH, Karter AJ: Rates of complications and mortality in older patients with diabetes mellitus: the diabetes and aging study. JAMA Intern Med 2014, 174:251-258.

49. Leung E, Wongrakpanich S, Munshi MN: Diabetes Management in the Elderly. Diabetes Spectr 2018, 31:245-253.

50. Lipska KJ, Montori VM: Glucose Control in Older Adults With Diabetes Mellitus-More Harm Than Good? JAMA Internal Medicine 2013, 173:1306-1307.

51. Lin CH, Sheu WH: Hypoglycaemic episodes and risk of dementia in diabetes mellitus: 7-year followup study. J Intern Med 2013, 273:102-110.

52. Monnier L, Lapinski H, Colette C: Contributions of fasting and postprandial plasma glucose increments to the overall diumal hyperglycemia of type 2 diabetic patients: variations with increasing levels of $\mathrm{HbA}(1 \mathrm{c})$. Diabetes Care 2003, 26:881-885.

53. Riddle M, Umpierrez G, DiGenio A, Zhou R, Rosenstock J: Contributions of basal and postprandial hyperglycemia over a wide range of A1C levels before and after treatment intensification in type 2 diabetes. Diabetes Care 2011, 34:2508-2514.

54. Yki-Jarvinen H, Kauppinen-Makelin R, Tiikkainen M, Vahatalo M, Virtamo H, Nikkila K, Tulokas T, Hulme S, Hardy K, McNulty S, et al: Insulin glargine or NPH combined with metformin in type 2 diabetes: the LANMET study. Diabetologia 2006, 49:442-451.

55. Lin CC, Yang CP, Li Cl, Liu CS, Chen CC, Lin WY, Hwang KL, Yang SY, Li TC: Visit-to-visit variability of fasting plasma glucose as predictor of ischemic stroke: competing risk analysis in a national cohort of Taiwan Diabetes Study. BMC Med 2014, 12:165.

56. Mehta HB, Mehta V, Goodwin JSJJoG: Association of Hypoglycemia With Subsequent Dementia in Older Patients With Type 2 Diabetes Mellitus. 2016, 72:1110.

57. Whitmer RA, Karter AJ, Yaffe K, Quesenberry CP, Jr., Selby JV: Hypoglycemic episodes and risk of dementia in older patients with type 2 diabetes mellitus. JAMA 2009, 301:1565-1572.

58. Joy NG, Mikeladze M, Younk LM, Tate DB, Davis SN: Effects of equivalent sympathetic activation during hypoglycemia on endothelial function and pro-atherothrombotic balance in healthy individuals and obese standard treated type 2 diabetes. Metabolism 2016, 65:1695-1705.

59. Lawes CM, Parag V, Bennett DA, Suh I, Lam TH, Whitlock G, Barzi F, Woodward M, Asia Pacific Cohort Studies C: Blood glucose and risk of cardiovascular disease in the Asia Pacific region. Diabetes Care 2004, 27:2836-2842.

60. Muggeo M, Zoppini G, Bonora E, Brun E, Bonadonna RC, Moghetti P, Verlato G: Fasting plasma glucose variability predicts 10-year survival of type 2 diabetic patients: the Verona Diabetes Study. Diabetes Care 2000, 23:45-50.

61. Wang A, Liu X, Xu J, Han X, Su Z, Chen S, Zhang N, Wu S, Wang Y, Wang Y: Visit-to-Visit Variability of Fasting Plasma Glucose and the Risk of Cardiovascular Disease and All-Cause Mortality in the General Population. J Am Heart Assoc 2017, 6:e006757.

62. Cryer PE: Hypoglycemia, functional brain failure, and brain death. J Clin Invest 2007, 117:868-870. 
63. Khunti K, Davies M, Majeed A, Thorsted BL, Wolden ML, Paul SK: Hypoglycemia and risk of cardiovascular disease and all-cause mortality in insulin-treated people with type 1 and type 2 diabetes: a cohort study. Diabetes Care 2015, 38:316-322.

64. Nicolucci A, Pintaudi B, Rossi MC, Messina R, Dotta F, Frontoni S, Caputo S, Lauro R: The social burden of hypoglycemia in the elderly. Acta Diabetol 2015, 52:677-685.

65. Song Y, Nam S, Park S, Shin IS, Ku BJ: The Impact of Social Support on Self-care of Patients With Diabetes: What Is the Effect of Diabetes Type? Systematic Review and Meta-analysis. Diabetes Educ 2017, 43:396-412.

66. Mayor S: Moderate exercise cuts type 2 diabetes risk but more is better, review finds. BMJ 2016, 355:i5605.

67. Moller G, Andersen HK, Snorgaard O: A systematic review and meta-analysis of nutrition therapy compared with dietary advice in patients with type 2 diabetes. Am J Clin Nutr 2017, 106:1394-1400.

\section{Figures}

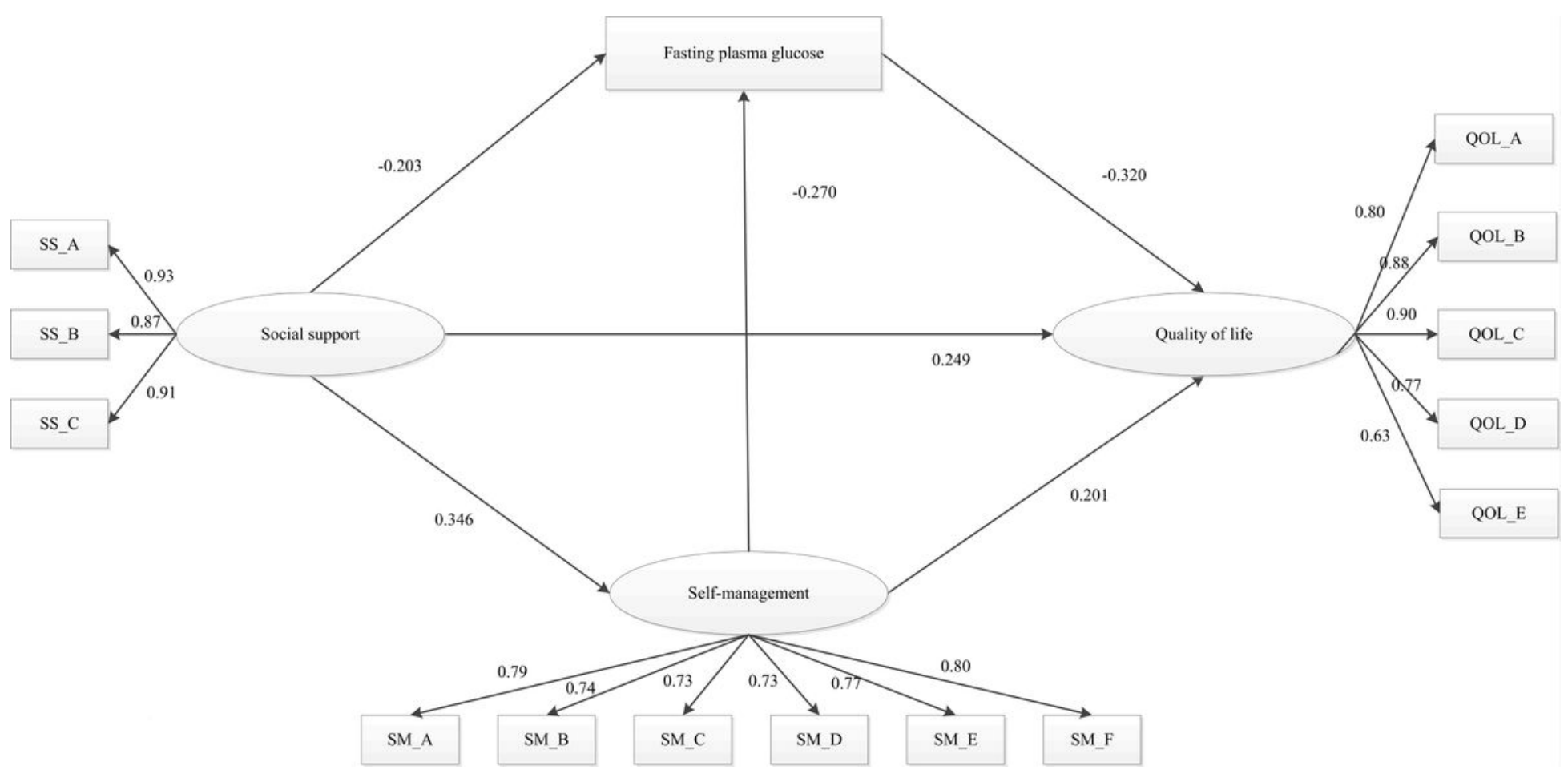

Figure 1

Multiple mediation models of social support and quality of life. Abbreviations. SM_A = diet control management; $S M \_B=$ exercise management; $S M \_C=$ medication management; $S M \_D=$ blood glucose monitoring management; SM_E = foot care; $S M \_F=$ hypoglicemia/hyperglycemia management; QOL_A = quality of life, activity domain; QOL_B = quality of life, emotion domain; QOL_C = quality of life, psychological feeling domain; QOL_D = quality of life, family burden domain; QOL_E = quality of life, diet domain; SS_A = family support; SS_B = friends support; SS_C = support from others. 


\section{Supplementary Files}

This is a list of supplementary files associated with this preprint. Click to download.

- DiabetesSupplement.docx 